\title{
Interactive comment on "The effects of morphology, mobility size and SOA material coating on the ice nucleation activity of black carbon in the cirrus regime" by Cuiqi Zhang et al.
}

\section{Anonymous Referee \#1}

Received and published: 4 October 2020

The comment was uploaded in the form of a supplement:

https://acp.copernicus.org/preprints/acp-2020-809/acp-2020-809-RC2-

supplement.pdf

Interactive comment on Atmos. Chem. Phys. Discuss., https://doi.org/10.5194/acp-2020-809, 2020. 